\title{
SAFA ÖNAL'IN HİKÂYELERİ
}

Sefa YÜCE*

\author{
$\ddot{O} z$
}

Safa Önal'ın hikâyeleri bin dokuz kurk sonrası yeni hikâye anlayışııın bir yansimasıdır. Bu dönemde, kentleşme olgusu ile birlikte bireyin sorunları gündeme gelir. Günlük hayatın akışl ve sıradan insanların yaşamları hikâyenin konusu olur. Önal'ın hikâyelerinde de çevrenin bireye etkisi ve bireyin iç çatışması belirgin olarak öne çıkar.

Önal'in hikâyelerinde vaka yok denecek kadar azdır. Onun hikâyelerinin kurgusal yönü, Memduh Şevket Esendal ve Sait Faik Abasiyanık'ın bir sentezi gibidir. Bu yönüyle durum ve kesit hikâyelerine yönelir. İyi bir gözlemci olan Safa Önal, sosyal değişimin bireye etkisini hikâyelerinde ustalıkla işlemesini bilir. Üslûp sahibi olan yazar, kendi dönemi içinde Türk hikâyeciliğine yeni bir renk katar. Hikâye yazarlığında olgunlaşması, onu senaryo yazarlı̆̆ına taşır. Bu çalışmada genel olarak Safa Önal'ın hikâyeleri değerlendirilmeye çalışıldl.

Anahtar Sözcükler: Safa Önal, Kentleşme Olgusu, Bireyin İç Çatışması, İstanbul, Dünyanin En Güzel Gemisi,

* Prof. Dr., Gazi Üniversitesi, Eğitim Fakültesi, Türkçe ve Sösyal Bilgiler Eğitimi Bölümü.

e-posta: sefayuce@hotmail.com

ORCID: 0000-0003-0030-5464

Geliş/Received: 18 Kasım 2021 / 18 November 2021

Kabul/Accepted: 6 Arallk 2021 / 6 December 2021 


\title{
THE STORIES OF SAFA ÖNAL
}

\begin{abstract}
Safa Önal's stories are a reflection of the new understanding of the story after nineteen forty. In this period, the problems of the individual come to the fore with the phenomenon of urbanization. The course of everyday life and the lives of ordinary people become the subject of the story. In Önal's stories, the influence of the environment on the individual and the inner conflict of the individual are prominent.

There are almost no cases in Önal's stories. The fictional aspect of his stories is like a synthesis of Memduh Sevket Esendal and Sait Faik Abastyanık. In this aspect, it turns to situation and cross-sectional stories. Safa Önal, who is a good observer, knows how to skillfully process the impact of social change on the individual in his stories. In addition, the writer, who has a good style, brings a new color to Turkish storytelling in his era. His maturation in story writing over time takes him to scenario writer in the next period. In this study, Safa Önal's stories are tried to be evaluated.
\end{abstract}

Keywords Safa Önal, the phenomenon of urbanization, The Inner Conflict of the Individual, Istanbul, The Most Beautiful Ship in the World.

\section{Giriș}

Hikâyenin edebiyatımızda boyut kazanması II. Meşrutiyet sonrasıdır. Millî Edebiyat dönemi ile hikâye türü büyük rağbet görür. Ömer Seyfettin, bu türün tematik olarak gelişimine önemli katkı sağlar. Refik Halit Karay'la da Anadolu realitesi hikâyenin ana teması olur. Şiirden sonra hikâye en çok rağbet edilen edebî tür hâline gelir. Mütareke ve Millî Mücadele dönemlerinde yazarlar, Anadolu'yu daha yakından tanıma imkânı bulurlar.

Cumhuriyet'in ilanından sonra hikâye, memleket gerçeklerine ve toplum sorunlarına eğilir. Bu dönemin hikâyesi konuşma dilini, hayat1 ve insanı ele alır. Küçük hikâyenin gelişimi hızlanır. 1923 sonrası hikâye türü iki ana kulvarda gelişir. Bu kulvarın ilki Mahmut Şevket Esendal'ın hikâye tarzıdır. O, hikâyeye yenilikler getirir. Vakaya dayanmayan hikâyeye yönelir. Esendal, iddiasız, gösterişsiz, bir anlatımın temsilcisidir. Çehov tarzı hikâyeciliği Türk edebiyatına taşır. Pürüzsüz dili, sıradan insanların iliş̧ilerini, sosyal hayatını etkili biçimde anlatır. Konu bulmakta zorlanmayan bir yazardır. Onun hikâyeleri estetik ve ahlâki boyutuyla hayatı bütün cephesiyle ortaya koyar (Lekesiz, 2000: 21).

Sabahattin Ali, 1930 sonrası kaleme aldığı hikâyelerinde köyü ve kırsal kesimi anlatır. O, Refik Halit Karay'dan sonra Anadolu insanının hayatını 
realist bir bakış açısıyla ele alır ve mütegallibe zihniyetini eleştirir. Ayrıca bürokrasinin yozlaşan yapısını ve bu yapının köylüye yansıyan yanlışlığını da dile getirir.

Sait Faik, hikâyeye yeni bir ivme kazandırır ve ona basamak atlatır. O, hikâye içinde yeni anlatım tarzları dener. Mektup ve röportaj havası taşıyan hikâyeler yazar. Üslûbunu ve cümle kurgusunu mensur şiir tarzına yaklaştıır. İnsanın iç dünyasına nüfuz eder ve sıradan insanı hikâyenin konusu yapar. O, edebî tür olarak hikâyeyi cezbedici hâle getirir. 1940 sonrası hikâye türü farklı bir boyut kazanır ve bu tür süreli yayınlar vasıtasıyla geniş halk kesimlerine ulaşır. Özellikle gazeteler, her hafta tefrika hâlinde hikâyeler yayımlar. Hikâyeye olan bu ilgi, yeni bir okur kitlesi de oluşturur.

Sanat ve edebiyatta dönemler, birbirinden tamamen kopuk değildir. Her yeni dönem, bir önceki dönemin mirasından yararlanır. Sanatta, yeni anlayış ve değerler, eskinin üzerine inşa edilir. Cumhuriyet döneminden önce hikâye yazmaya başlayanların birçoğu yeni dönemde de eserler vermeye devam ederler (Akyüz, 1982: 193). Eskilerden beslenen, ilk imzalı yazısını 1945 yılında Bilmece dergisinde yayımlayan hikâyecilerden biri de Safa Önal'dır. Onun iyi bir hikâyeci ve senarist olmasında aldığı eğitim ve okuma sevgisinin büyük rolü vardır. Bu süreç aynı zamanda kendisini inşa etme evresidir. $\mathrm{O}$, bu hususta şu değerlendirmeyi yapar:

"Reşat Nuri Güntekin'in ortaokul kitabımızdaki 'Eski Bir Yara' adlı hikâyesi, bütün ömrümü çizmiştir, bugüne kadar beni hâlâ etkilemekte, götürmektedir. Diğeri Selami İzzet Sedes'tir... Maurice Leblanc'in Arsen Lüpen'lerini orijinalinden daha güzel bir dille Türkçeye aktardığı söylenirdi. Gerçekten de o Türkçe, tadına doyulmaz, tadından yenmez bir Türkçedir... Ben on bir, on iki yaşlarında okumaya başlamıştım. (...) Ben bir defa okuma açlığ1 çekmekteyim hep. Yani yetmemektedir. İtikat sahibiyim ama şu espriyi yapabilirim; keşke öbür tarafa kitaplarla gidebilsem! Çoğumuzun bizden öncekileri okumadığını, ya da şöyle bir göz gezdirdiğini, kuş uçuşuyla tepelerden bakıp geçtiğini düşünmekteyim. Düşünmekte değilim, o lafi da sevmiyorum!.. İnanmaktayım buna. Kendimizi okumadık. Kendimizi iyice bıraktık, okumuyoruz (Arpa, 2009: 50-51)”.

\section{Dünyanın En Güzel Gemisi}

Safa Önal, lise yıllarından itibaren Hafta, Yelpaze, Hayat dergilerinde ve Milliyet gazetesinde hikâyeler yazar. Ayrıca Türk Düşüncesi ve Yelpaze

dergilerinde de yazı işleri müdürlüğü yapar. Önal, hikâyelerini Dünyanın En 
Güzel Gemisi adıyla kitaplaştırır. On dokuz hikâyeden oluşan kitapta, Peyami Safa'nın bir tanıtım yazısı yer alır.

Bir yazarın üslûp sahibi olabilmesi anlatım tarzına bağlıdır. Üslûbun farklılığını ortaya koyan ve belirleyen temel ölçüt de nasıl anlattığı sorusudur. Safa Önal, hikâyelerinde şiirsel bir üslûp kullanır. Peyami Safa'nın ifadesiyle "şiir yerine hikâye yazan bir şairdir." Önal, kısa hikâyeler yazmayı tercih eder, bu hikâyelerin bir kısmını daha sonra senaryolaştırır. Onun kitabında yer alan hikâyelerin ilki Vesaire Vesaire'dir. Hikâye, Ayşe ile Sabahattin'in aşkını anlatır. Ağabeyinin manav dükkânında çalışan Sabahattin, uzun süre Ayşe ile arkadaşlık eder. Aralarında bir sevgi bağı oluşur. Sabahattin, bir karpuz sergisi açar ve işleri umduğundan iyi gider. Komşular ve esnaf da ona yardım ederler. Bu arkadaşlık ilişkisi mutlu sonla biter. Hikâyenin kurgusu dostluk üzerinedir. Bu yönüyle Vesaire vesaire, Memduh Şevket Esendal'ın hikâye anlayışı ile benzerlik gösterir. Hikâyede, yazar anlatıcı özne konumundadır. "Ben ikisine ayrı ayrı göz kırpardım... Sabahları susar, Ayşe'yle Tarabya'dan döndügü günden beri girmediği önünden geçer, bir boy gider, döner, sonra yine gider, köşeyi dönüp kaybolurdu..." Hikâyede zaman, yaz mevsimidir. Nesnel zaman, 1950'li yıllardır. Ana mekân İstanbul'dur. Hikâyede kişiler, Ayşe, Sabahattin, Sabahattin'in ağabeyi, Fırıncı Boğos'un oğlu ve Elektrikçi İstepan'dır. Esnaflar arasında yardımlaşma duygusu yaygındır. Semt ve esnaf kesimi Sabahattin'i destekler, onu korur. Azınlıkların da olduğu bu semtte huzur vardır. Hikâye, şiirsel bir anlatım tarzıyla okuyucunun ilgisini çeker, onda merak uyandırır ve düşündürür.

Ardından hikâyesinin konusu, eşinden ayrılan adamdır. Oğlu Orhan'la kalan adam, eşinden ayrılmanın şaşkınlığ i içindedir. Annenin evden gitmesi, Orhan'1 olumsuz etkiler. Çocuk durgundur ve önündeki çorbayı içmek istemez. Adam, onu neşelendirmek için çabalar. Oğluna, sınıfını geçerse bisiklet alacağını söyler. Bazen de asabileşir ve çocuğu annesinin yanına göndermekle tehdit eder. Orhan'a galiz sözler söyler: "Ö̈yle bakma yüzüme. İndir bakışlarını hayvan herif! Yeter be, akşamdan beri yaptığın numara... Ve dinle. İşine gelirse, gelmezse, sen de onun yanına defolursun. İşte bu kadar!" Adam, eşini kendisini sevmemekle suçlar. Ona çok tepkilidir ve ondan kurtulduğu için Tanrı'ya şükreder. Fakat buna rağmen zaman zaman gelgitler yaşar. Oğlunun teselli etmeye çalışır. O, bütün bu olumsuz gelişmelerden eşini sorumlu tutar. Mekân, ev ortamıdır. Kurgu, psikolojik gerilim ve iç çatışma üzerine inşa edilir. Anlatıcı, gözlemci konumundadır ve nesnel bir tavır sergiler. Hikâyede beş kişiden bahsedilir: Adam, oğlu Orhan, ayrılan eş ve Seher. Bir de Orhan'ın arkadaşı Aysel. Hikâyenin merkez kişisi olan adam sürekli iç çatışma yaşar. 
Uyku Üstüne Hikâye'si, bir tohumun gelecek ile ilgili düşlerini anlatır. Konu, tohumdur. Hikâyenin kurgusu, ideal ile realitenin çatışmasıdır. Anlatıc1, gözlemci konumunda ve nesneldir. Hikâyede belirli bir mekân yoktur. Uzun zaman dilimi, sıkıştırılmış süreç içinde anlatılır. Tohum, hülya içindedir. Aslında bir ağaç tohumudur, fakat nasıl bir ağacın tohumu olduğu da belirsizdir. Tohum, ne olursa olsun insanlara faydalı olmayı amaçlar. Paşanın oturduğu bir masa, mimber, kürsü veya çekmece olmayı düşler: "Bütün ömrü boyunca, kendisinin etrafinda tek bir defa toplanılmalıyd,, fazla değil... Fakat dünyada bütün masaları kıskançlıktan gebertecek bir toplantı..." Endişeleri de vardır. En büyük endişesi, kibritlik bir kavak ağacı veya hastane bahçesinde çam ağacı olmaktır. Tohumun hiçbir düşü gerçekleşmez. Hayallerle yaşayan tohum ancak darağacı olur. Yazar, hikâyede bir iç çözümleme yapar.

Gizli Sıtma'nın konusu, tutkudur. Hikâyeyi, özne anlatıcı bize aktarır. Nesnel zaman ellili yıllardır. Hikâyede iki yaz mevsiminden söz edilir. Bu da iki yıllık zamana tekabül eder. Tek taraflı aşk ve tutku üzerine kurulan hikâyenin kurgusu, iç çözümlemeyle anlatılır. Erkeğin yaşadığı iç çatışmanın boyutu, genç kızı kaybedeceği endişesiyle zaman zaman tırmanır. Onun dikkatini çekme çabaları da gerekli sonucu vermez. Erkek, genç kızı sadece kendisine yakıştırır. Kız için zihninde planlar yapar, kaleme aldığı bir hikâyeyi ona okur. Bu bir aşk itirafıdır. Genç kız, hiç üzerine alınmaz, sevgilisinin beklediğini söyleyerek mekândan ayrılır. Erkek için genç kızın tavrı ümidin bitişi ve yıkımın başlangıcı olur.

Dalga hikâyesinin konusu yaşamdan izlerdir. Özne anlatıcı, flaschback tekniği ile hikâyeyi aktarır. Dalga adını ise yazar, bir imge olarak kullanır. Hikâyede yaşananlar, ard arda gelir ve birbirini takip eder. Bu bir nevi karnaval havası ve denizdeki dalgalar gibidir. Hikâyede zaman, karartma gecelerinin hüküm sürdüğü İkinci Dünya Savaşı yıllarıdır. Okul yılları, aşklar, eğlenceler, İstanbul'un değişik mekânlarında yaşananlar, radyonun bıraktığı etkiler, Beyoğlu ve Tarlabaşı'nda arkadaşlarla yaşanan maceralar hikâyenin kurgusunu oluşturur. "Afif'ten Vecdi'den Zeki'den derken sevgilimden bahsediyoruz. Yarım bir el kapıdan balıkları uzatıp, çekiliyor. İlk kadehten sonra susmağı seviyorum. Üçüncü, dördüncüyle içimden şiir yazmak geliyor. Limandaki gemilerin bacalarına yorgun kuşlar konduruyorum..." Hikâyede haz ve hedonist zihniyet ön plana çıkar.

Baba-Ŏgul'un konusu, aile içi çatışmadır. Hikâyede, eşinden ayrılan adamın kız kardeşi Huriye ve oğluyla yaşadığı sorunlar anlatılır. Aile içi çatışmanın bütün boyutları ile yaşandığı hikâyede, kız kardeş, yaşlı ağabeyinin boşanmasına sebep olur. Huriye evlenememiş biridir. Fakat bunun nedeni olarak yaşlı ağabeyini suçlar: "-Eve gelen görücülerden sen 
bile bıkmıştın. Sokağa çıkarken nazarlık takmasam, akşam ateşler içinde yatardım. Sonra sen beni, o lânet karı yüzünden, sipsivri ortada bıraktın." Huriye'nin sözlerine ve samimiyetine inanmayan ağabeyi, onu yalanc1 olmakla suçlar. Huriye, baba ile oğlunun da arasını açar. Onları birbirine düşman yapmaya çalışır. Ağabeyi, kız kardeşinin sinsi planlarının farkındadır. Bunu biraz geç anlar: "-Bugüne kadar sinsi sinsi hep fikrimi çeldin. Beni oğluma düşman ettin. Kıskançlı̆̆ından gebereceksin. Evlenip, çocuk sahibi olamadın diye bize düşman kesildin." Yeğeni de halasının art niyetini bilir, onun şirin görünme çabalarına inanmaz. Yirmi yaşındaki genç, halasının sakladığı parayı alır ve evden uzaklaşır. Hikâyede anlatıcı, gözlemci konumundadır. Huriye, bir ailenin dağılmasına sebep olur. Hikâyede uzun zaman dilimi, sıkıştırılmış zaman dilimi içinde anlatılır.

Üçe bölünmüss saat hikâyesinin konusu, bir hülya adamıdır. Adamın sevdiği kız, kendisini kardeşiyle aldatır. İhanetin bedeli onun için ağır olur. Sevdiğinden başka kimseyi görmeyen adam, aslında bir karasevdalıdır. $\mathrm{Bu}$ bir nevi onun ölümü gibi olur. Bulunduğu şehirden kaçar, fakat yine de kızı unutamaz. Onu unutmak için kendini oyalamaya çalışır: "Şehirden kaçmakla ne kazanmıştı?.. O'ndan kaçamadıktan, onu unutamadıktan sonra, bir öğle vakti, Ege denizinde, yağmur altında olmanın ne faydası vardı?..(...) Acaba hiç ümit yok muydu? Acaba bir daha bu şehre dönmezler miydi? Yahut sadece biri...Hangisi olursa olsun..." Bu düşünceler içinde olan adam avare avare dolaşır ve hayal kurmakla meşgul olur. Hikâyenin anlatıcısı hem gözlemci hem yorumlayıcı konumdadır. Adam, sürekli iç çatışma yaşar ve zaman zaman bunalıma girer. Hikâyede, bireyin yaşadığı sendrom, zamanla psikosomatik hâle dönüşür. Mekân, İstanbul'dur. Uzun zaman dilimi içinde geçen hatıralar, sıkıştırılmış zaman diliminde anlatılır.

Hikâye Bu Ya'nın konusu, özlemdir. Hikâyenin kişisi, hayatı sever ve başka hiçbir şey düşünmez. Hikâyenin kurgusu, sevgiliye yazılan bir mektup gibidir. Belirli bir mekân ve zamandan söz edilemez. Hikâye kişisi, yaşadığı her şeyi paylaşmaya çalır. Aslında yaşadıklarını ve hayallerini anlatarak rahatlamak ister. Sevgilisinin beraber olduğu adam aklına gelir. Bu adamın onu kandırdığını düşünür. $\mathrm{O}$, sadece sevgilisini değil, yakışıklı, dikkat çekici ve zenginleri de kıskanır. Bazen de her riski göze alır, fakat sonradan vazgeçer: "Söz olmasa, kapıma polisler gelmese, başına iş açılmazsa bilirim yapacağımı... Seni kaçırmak geliyor aklıma ama cesaret edemiyorum. Evvelâ kiracıları, sonra da yolları, meydanı gözlesem, ortalıkta kimsecikler olmadığını görünce seni evime alsam... Yok aklından geçtiği gibi değil... (...) Ben mi? Yalnızım. Ne kadın, ne çocuk... Hasretlik içinde geçiyor ömrüm. Yalnızlık zor...İki ufak oda yalnızlıkta büyüyor da büyüyor.” Kişi 
merkezli bu hikâyede bireyin iç dünyası ve onun kendiyle ilgili çatışması anlatılır. Hikâyede anlatıcı özne konumundadır.

Müzikli Tarife hikâyesinin konusu, bir lokal eğlencesidir. Hikâye, egzotik unsurlar taşır. Adam, müzikli bir lokale gider. Burada, müzik ritmi içinde orkestrayı gözlemler. Hikâyede zaman bin dokuz kırk beş ve ellili yıllardır. Bu yıllarda savaşın olumsuz yansımaları yakından hissedilir. Savaş, alışılmış pek çok şeyi değiştirir. Oğlundan uzakta olan anne Hans'tan bahseder. İki ayağı olmayan Hans'ın yaşamı merak konusudur. Kendisini yaşlı ve hasta hisseden kadının gelecekle ilgili bir beklentisi de yoktur. Adam, eşini bir an önce oğlunun yanına göndermek ister. Onun da sıkıntıları vardır, fakat bu sıkıntılar, yüklü bir alacak davasını kazanmasıyla sona erer. Müzik dinlediği lokalde hesabı isteyen adam, rakamı görünce şaşkınlığını gizleyemez ve tepki gösterir. Garson, bu canlı müziğin tarifesidir diyerek, adamı yatıştırmak ister. Hikâyede, iki anlatıcıdan söz edebiliriz. Anlatıcı, hem gözlemci hem de özne konumundadır.

$\boldsymbol{E v} \boldsymbol{K \boldsymbol { l z } \iota}$ 'ında konu, evlilik hayali kuran gencin yaşadığı hüsrandır. Kızla buluşan genç, onu yakından tanımak ister. Fakat kızın gizemli bir tarafi dikkatini çeker. Onun bu tavrı, gençte bazı şüphelerin uyanmasına neden olur. Genç, kızın doğruları söylemediğini ve kendisi ile ilgili bilgileri sakladığını düşünür. Kız, aslında gencin şüphesinin farkındadır. Adının Nevin olduğunu söyleyen kız, genci inandırmaya çalışır. Genç, kızla birçok mekânı gezer ve eğlenir. Kız ise, gidilen mekânların hepsini bilmektedir. Bu durum, gencin şaşkınlığını biraz daha artırır. Harem'de oturduğunu ve babasını hatırlamadığını söyleyen kız, genci ikna etmeye çalışır. Genç, kızı test etmek ve niyetini anlamak için onu evine davet eder. Kız, hiç tereddüt etmeden daveti kabul eder. Genç, kızın evini bildiğini ve bu evin eskiden onun da oturduğu bir randevu evi olduğunu öğrenir. Bu durum, genç için trajik bir son olur ve böylece evlilik hayali biter. Hikâye, özne anlatıc1 tarafindan gösterme yöntemi ile anlatılır. Ana mekân İstanbul'dur. Ev Kızı, tipik bir durum hikâyesidir ve hikâyede, psikolojik unsurlar öne çıkar.

Hastanede hikâyesinde konu, genç Orhan'ın ölümüdür. Annesi Naciye, oğlunu babasız büyütür. Orhan, söz dinleyen bir çocuktur. Fakat onun hastalanması, annesini zor durumda bırakır. Dayısı da yeğenine bir baba gibi davranır. Orhan, annesine bazı serzenişlerde bulunur ve sınıfını geçtiği halde bisiklet almamakla itham eder. Dayısı da yeğenini söz dinlemediği için nankör olmakla suçlar Tedavi olmak için hastaneye gelen Orhan iyileşemez ve ölür. Onun iyileşmesini bekleyen anne büyük bir trajedi yaşar ve her şey alt üst olur. Hikâyede anlatıcı, hem özne hem de gözlemci konumdadır. Ana mekân hastane ortamıdır. 
Ĕger egzotik bir hikâyedir. Konusu, sürprizdir. Hikâyede, karsını memnun etmek isteyen adam bazı düşler kurar. Bu düşleri gerçekleştirmek için harekete geçer. Fakat bunlar kolay gerçekleşebilecek düşler değildir. Adam birçok suç işlemiş sabıkalı biridir. Eşine geçmişi unutturmak ve onu mutlu etmek için adım adım planladığı eylemleri uygulamaya çalışır. Maddi geliri olmayan adam, yasa dışı işler yapar. Kuyumcudan elmas küpeler ile bilezikler aşırır. Korku içindedir. Eskisi gibi soğukkanlı değildir. Her an yakalanma endişesi yaşar. Eşi Katherin'e ulaşmak üzereyken, kapıda polislerin ayak seslerini işitir ve onların gölgesini görür. Bu durum sona gelindiğinin de bir işaretidir. Adamın kurduğu düşler gerçekleşmez ve sonu hüsranla biter. Hikâyede mekân çok katlı bir asansördür. Adam, seksen üçüncü kattan sırayla aşağıya inemeye çalışır. Otuz üçüncü katta ise kuyumcu yer alır. Polislerin ona ulaşmaya çalıştığı yer ise on birinci kattır. Hikâyede anlatıcı gözlemci konumundadır.

Günlerden Bir Gün hikâyesinde konu, kız arkadaşını bekleyen gençtir. Kızla sözleștiği yere gelen genç, heyecanla onu bekler. İstanbul'da günlük hayat hızla akar. Ayaspaşa'dan Mete Caddesi'ne bakan genç, dolmuşların Arnavutköy ve Emirgan'a hareketlerini izler. Yağmur yağar, güneş açar, zaman ilerler, fakat kız arkadaşı bir türlü gelemez. Vakit geçirmeye çalışan genç, kendini oyalayacak ortam arayışına yönelir. Kız arkadaşı ile ilgili hayaller kurar. Artık beklemekten usanan genç, serzenişlerde bulunur ve sinirlerini yatıştırmaya çalışır. Evine dönmeye karar verir. Hikâyede ana mekân olarak İstanbul'dur. Hikâye anlatıcı özne konumundadır.

Sabaha Karşı hikâyesinde konu, vapur bekleyen dört arkadaştır. Boğaz'da bekleyen dört arkadaşın üçü erkek, biri kızdır. On yedi yaşında olduğu tahmin edilen kız, yanında oturan erkeğe ailesinden bahseder. Babası alkolik olan kızın, annesi de geçen yıl ölmüştür. Bir an önce evine dönmek isteyen kız diğerleri gibi vasıta bulamaz. Kız, sıkıntıdan değişik tavırlar sergiler. Yanındaki adam, onu İngiliz sefaretinin arkasındaki evine götürmek ister. Ablasının ölüm haberini alan kı, üzülür ve ağlamaya başlar. Yanındaki adam bir taksiye biner ve gider. Küçük bir motor bulan diğer üç kişi, karşıya geçmek için hareket ederler. Kıza dikkatli bakan gençlerden biri ablasının adının Semiha olup olmadığını sorar. Kız şaşırır ve o da gence Ahmet misin diye seslenince dügüm çözülür. Hikâyede ana mekân Üsküdar'dır. Anlatıcı, özne ve gözlemci konumundadır.

Ay Çizgisi hikâyesinde konu sevgilidir. Adam günlük hayatın akışı içinde anılarına yolculuk eder. Mevsim değişmekte, yaz sona ermektedir. Vitrinler ve pazar yerleri avare insanlarla doludur. Adam, ilk sevgilisini ve Erenköy'de ağaç altında oturduğu zamanları hatırlar. Yatılı okul yılları gözünde tekrar canlanır. Yine gecenin birinde sevgilisi ile birlikte Moda ve 
Kalamış arasında kiraladıkları kayığı hatırlar. Sevgilisiyle küs olan adam, onunla barışmayı düşünür. Fakat zihni karışıktır, sevgilisinden ayrılmanın hüznü onu kendisiyle muhasebe yapmasına neden olur. Hikâyede anlatıcı özne konumundadır. Ana mekân İstanbul, zaman ise, sonbahardır.

Fatma'da konu, memleketiyle bağı kopmuş kızlardır. Yazar hikâyede, ailesi ve memleketi ile bağını koparmış Fatma tipi ile binlerce kızı anlatır. Fatma ve benzerleri, İstanbul'da korku ile karışık bir hayat yaşar. Bu kente uzaktan gelenler şaşırırlar ve hayatın gelgitlerini yaşarlar. Fatma da bu tiplerden biridir. Hep arayış içinde, yarı ürkek, yarı çekingen bir tavır sergiler. İlkokul, enstitüsü derken anne ve babasını kaybeder. Kendini yeni bir ortamın içinde bulur. Fatma ve onun gibiler, eğlence mekânında, şehir hatlarında, günlük alışveriş merkezlerinde, sıkça görülür. Aslında İstanbul'un her semti Fatmalarla doludur. Hikâyede anlatıcı gözlemci konumundadır. Ana mekân İstanbul'dur.

Yllan Hikâyesi' inde konu eşiyle anlaşamayan adamdır. Sürekli yağan yağmur evde tartışmaya neden olur. Adam yaşlı, eşi ise gençtir. Genç kadın, yağmuru hiç sevmez. Çinko kaplı balkondan sürekli yağmur gürültü gelir. Havanın kapalı olması da kadını gerer ve aralarında tartışma başlar Yaşlı adam, tartışmadan sonra komşusuna gider. Komşusu ise bir gençtir. Yaşlı adam, ona eşiyle ilgili yaşadığı sorunları anlatır. Genç adama göre asıl sorun yağmur değil, yaş farkıyla ilgili başka sorunlardır. Ayrıca yağmurun sürekli yağması bir bahanedir. Hikâyede mekân bir apartman dairesidir. Ana mekân ise İstanbul'dur. Hikâyenin anlatıcısı özne konumundadır. Zaman, yaz mevsimidir. Hikâyede, bireyler çatışma çatışma ön plana çıkar.

Sen Olmayınca hikâyesinin konusu bir yılbaşı gecesidir. Genç adam, yılbaşı gecesi bir eğlence mekânına gider. Karın yağışını bekler, fakat kar bir türlü yağmaz. Artık ümidini yitirir. Bir arayış içindedir ve çocukluğu aklına gelir. Bostanc1'da bulunduğunu bu mekânı sever. Rahmetli arkadaşı Ferit'le dinlediğini şarkıyı hatırlar. Sevgilisini düşünür ve geç vakte kadar bu mekânda kalır ve alkol almak ister. Bir anda kız arkadaşı sürpriz yapar ve yanına gelir. Bu arada dışarıya kar yağmış ve her yeri kaplamıştır. Hikâyede zaman aralık ayıdır. Mekân Bostancı'dır. Anlatıcı, özne konumundadır.

Dünyanın En Güzel Gemisi'nde konu, geçmişe özlemdir. Adam, çocukluk dönemini ve işportacıları hatırlar. İlk kez seyrettiği sinema filmi gözünde canlanır. Donanma geceleri rüyalarını süsler. Bu gecelerde, havai fişekler atılır, fener alayları düzenlenir ve trampet sesleri etrafa yayılır. Adam, yatılı mektep yılları ile mahzun geçirdiği geceleri tekrar yaşar. Kızkulesi'ne bakan odası aklına gelir. Anneannesine gidişini, dayısının harçlık verişini, ak saçlı ihtiyarların gazete okuyuşlarını tekrar yaşar gibi 
olur. Dinlediği şarkılar, şarkıların çağrışımları ve sevdiği aklına gelir. Bu hisle, kendisini kıyılara ulaştıran güzel bir gemi hayal eder. Hikâyede anlatıcı, özne konumundadır. Ana mekân İstanbul'dur

\section{Hikâyelerin Karakteristik Özellikleri}

Safa Önal, 1945 sonrası yazarlı̆̆a adım atar. Sağlam bir kültür birikimi olan ve Türk milletinin kültür kodlarını gayet iyi bilen yazar, edebî eserleri okuyarak kendini inşa eder. Yazarlığı meslek olarak seçer ve işe hikâye yazarak başlar. Sanat ve bilimde eğitim muhakkak gereklidir, fakat bireyde doğuştan gelen bazı nosyonlar olur. Bu nosyonlar, zamanla bir yetenek olarak ortaya çıkar ve işlenerek gelişir. Önal'ın hikâyeci olarak başladığı yazarlık serüveni, senaryo yazarlığı olarak devam eder.

Onun hikâyelerinde, Cumhuriyet sonra değişen sosyal hayat ve kent olgusunun izleri görülür. Günlük hayat, bireyin iç dünyası, aşk, sevgi, psikolojik sorunlar ve nesil çatışması hikâyelerinde en çok işlenen temalardır. İyi bir gözlemci olan yazar, bireyin iç dünyasına nüfuz etmeye çalışır. Önal'ın hikâyeleri bir nevi Memduh Şevket Esendal ile Sait Faik Abasıyanık hikâyelerinin bir sentezi gibidir. Fakat o hikâyelerinde kendi özgü bir üslûp anlayışı oluşturur. Bu üslup, mensur şiir tarzı edası taşır. Aslında Önal "şiir yerine hikâye yazan bir şairdir."

"Her hikâyeci bize eseri ile hayatın ve insanın ayrı bir yönünü gösterir. Hikâye, anlaşılması son derece güç olan hayatın ve insanın içine adeta bir pencere açar. Günlük hayatta biz hayatı ve insanı dıştan görürüz ve pek az anını biliriz. Hikâyeci bu dış görünüşün arkasındaki gerçekleri keşfeder. Güzel hikâyelerin hemen hepsinde, bilinmeyen bir gerçeğin ifşası vardır (Kaplan, 1978:10). Peyami Safa'ya göre “Önal'ın hikâyelerinde samimilik ve bu kendine mahsusluk vardır. Sahtelikten ve bayağılıktan eser görülmez. Kuklalar standart tiplerden daha canlı, daha başka ve daha derinliklidirler (Safa, 2017:11)."

Safa Önal'ın hikâyeleri olaya dayanmaz. Onun hikâyeleri durum ve kesit üzerine kurgulanır. Okur, hikâyenin başlığı ile içerik arasındaki ilgiyi bazen metni okuduktan sonra kavrayabilir. Bazen de hikâye sürpriz biçimde bitebilir. Kısa hikâye tekniğini başarıyla uygulayan Önal, realist anlayışı benimser. $\mathrm{O}$, hikâyelerinde çoğunlukla bireyin iç dünyasına yönelir ve bireyin açmazlarını gündeme getirir.

\section{Sonuç}


Safa Önal, hikâyenin edebiyatımızda büyük itibar kazandığı dönemde ilk hikâyelerini yayımlar. Onun hikâyelerinde günlük hayatın sıradanlığı, arkadaşlık ilişkileri, ailevi sorunlar, bireyin iç dünyası ve İstanbul'daki sosyal hayatın pek çok yansımaları görülür. Kısa hikâye tekniğini başarıyla uygulayan yazar, sağlam bir üslûba sahiptir. Onun hikâyelerini cazibeli kılan unsurlardan biri de iyi bir gözlemci olması ve insanın iç dünyasına nüfuz etmesidir.

Safa Önal'ın hikâyelerinde belirgin özellik olarak İkinci Dünya Savaşı sonrası gelişen yeni hayat anlayışının bireye yansımalarıdır. Bu hikâyelerde, kent olgusu ile birlikte bireydeki iç çatışma ve uyum sorunu yeni bir boyut kazanır. Ayrıca onun hikâyeleri kurgusal yönü itibariyle klasik vaka anlayışına dayanmadıkları için okurun da dikkatini çeker. Önal, hikâyelerindeki bu yapısal özelliği senaryolarına uygular ve bunda da başarılı olur.

Onun yazar olarak kendini inşa etme sürecinde Türk hikâye geleneğini iyi bilmesi ve detaylı okuma çalışmalarının büyük payı vardır. Bir hikâyeciyi, diğerlerinden farklı kılan unsurlar, insana bakış açısı ve üslûp farklılı̆̆gdır. Sefa Önal'ın hikâyeden sonra senaryo yazarlığına yönelmesinde bunun da büyük payı vardır.

\section{KAYNAKÇA}

AKYÜZ, K. (1982). Yeni Türk Edebiyat1, Türk Ansiklopedisi, Ankara: MEB.

ARPA, Y. (2009). Ne Kadar Gamlı Bu Akşam Vakti, İstanbul: Tr. İş Bank. Yay.

LEKESİ, Ö. (2000). Türk Öykücülüğü Özel Sayısı 46/47, Ankara: Hece Yay.

ÖNAL, S. (2017). Dünyanın En Güzel Gemisi Hikâyeler, İstanbul: Profil Kitap. 